\title{
An Ensemble Approach Modelling to Assess Water Resources in the Mékrou Basin, Benin
}

\author{
O. U. Charlene Gaba ${ }^{1,2, ~ * ~}$, I. Eliezer Biao, ${ }^{1,2}$, A. Eric Alamou ${ }^{2}$, Abel Afouda ${ }^{1,2}$ \\ ${ }^{1}$ West African Science Service Center on Climate Change and Adapted Land Use, GRP Water Resources, Cotonou, Benin \\ ${ }^{2}$ Laboratory of Applied Hydrology, Faculty of Science and Techniques, University of Abomey-Calavi, Benin
}

Email address:

gaba.charlene@gmail.com (O. U. C. Gaba), biaoeliezer@yahoo.fr (I. E. Biao), ericalamou@yahoo.fr (A. E. Alamou), aafouda@yahoo.fr (A. Afouda)

\section{To cite this article:}

O. U. Charlene Gaba, I. Eliezer Biao, A. Eric Alamou, Abel Afouda. An Ensemble Approach Modelling to Assess Water Resources in the Mékrou Basin, Benin. Hydrology. Vol. 3, No. 2, 2015, pp. 22-32. doi: 10.11648/j.hyd.20150302.11

\begin{abstract}
The aim of the study was to test the possible adequacy of an ensemble model to reproduce the observed flows in the Mékrou basin and in what measure this ensemble simulation could be used instead of a unique model. Single model applications showed shortcomings in terms of simulating both high and low flows at the same time. Thereby, the models were calibrated according to two different modes (high and low flows) and they were tested further through the elaboration of three various ensembles. The observed hydrographs were separated in three parts each in order to evaluate with much precision which model or ensemble fits best the hydrographs. On the basis of the Root Mean Squared Error (RMSE), the models and derived ensembles were assessed using discharge data. In this paper, the comparison is made between models, mean and median ensembles. Good results were obtained for all models and ensembles but the best ones were achieved by the mean-based ensemble.
\end{abstract}

Keywords: Hydrological Ensemble Modeling, Water Resources Assessment, Hydrograph, Mékrou Basin

\section{Introduction}

Mékrou catchment is a subcatchment of the Niger basin. This catchment faces numerous challenges in terms of water resources management. Water in this catchment is mainly used for agriculture: rain-fed agriculture, but also market gardening and rice growing. It is worth mentioning that agricultural activities are the base of the local economy of the Mékrou catchment $[1,2]$. Livestock farming is also an important source of water consumption as well as fish breeding and fishing. Natural water reservoirs suffer from erosion and are getting filled with sand.

Population growth as well is one of the factors of pressure on water resources reducing water availability per capita [3]. Moreover, West Africa is greatly impacted by the Climate Change in terms of water resources (availability and variability) [4-8], especially a reduction in water supply and crop yields [2] making water resources management a greater challenge. Given these major water related challenges, a project entitled " Water for growth and poverty reduction in the transboundary Mékrou basin" commonly called the "Mékrou Project" was jointly prepared by the global Water Partnership (GWP) and the Joint Research Centre (JRC) of the
European Union, in close collaboration with the key partners of the West African Region [9]. "The Project aims at supporting the green economic growth and poverty reduction in Burkina Faso, Benin and Niger, through water management in developing areas" [9]. The Project was launched in 2014 in Ouagadougou [10].

One of the main components of the Project is the understanding of the Water Balance. With regard to this component, various studies conducted by countries and institutions in the framework of this project concluded that there is a real problem with the knowledge of the water resources and that single model application was not fully satisfying [9]. That is why a multi-model approach is proposed. Some usual methods in Climate modeling (namely ensemble modeling) are more and more applied in hydrological modeling [11-13]. Generally, a model under certain calibration conditions is not able to reproduce all the parts of the hydrographs. That is why this ensemble modeling technique is explored. It may help improve the assessment of water resources and reduce the uncertainty originating from the model. Todini (2007) gave in his paper the example of a combination of two different modelling approaches that led to a better model. In fact, the new derived model benefits from the robustness of the first model and the adaptability of the 
second one [14].

To date, no such a study of ensemble modelling has been performed for the Mékrou catchment, although various models have been applied.

Another interest of the current research is the assessment of the adequacy of the hydrological model MODHYPMA to simulate flows in the Mékrou basin. This research allows us to test this new hydrological model based on the physics principle of Least Action. According to this principle, the energy spent by water to move from a place to another one is optimum. The use of this principle in Hydrology allows to minimise uncertainties and to have a limited number of parameters: three (3). This will also facilitate the generation of discharge data in a context of its limited availability. Beven (2007) points out the fact that all environmental modellers recognise that something is learned about the performance of the modelling process in every application to a new site [15].

The paper first presents the research site and data. The methodology is then exposed in detail. Finally results are then given and discussed.

\section{Data and Methods}

\subsection{Description of the Investigated Catchment}

Our study focuses on the Mékrou catchment (5 708 km2) located in the north of Benin at the outlet of Kompongou $2^{0} 12^{\prime} \mathrm{E}-11^{0} 24^{\prime} \mathrm{N}$ (see Figure 1). With an elongated shape, it covers three main towns which are Kérou, Kouandé and Péhunco.This catchment belongs to the beninese part of the Niger basin.

The eastern border of the catchment is the Atacora mountain. The highest point is at Kampuya $(641 \mathrm{~m})$ in the surroundings of Kouandé. The lowest point $(259 \mathrm{~m})$ is located in the surroundings of Kérou and precisely in the bed of the river Mékrou. The mean elevation is estimated at $369.8 \mathrm{~m}$ and the average slope is about $2.47 \%$.

Soils are mainly composed of Gleyic Arenosols, Eutric Plinthosols and Acrisols. Geology is composed by three old sedimentary series $[1,16]$. The land use is characterized by the dominance of the savannah. There exists two protected forests: Kouandé and Mékrou [1].

The analysis of precipitation data (from 1958 to 1997 for Kérou and from 1932 to 2010 for Kouandé) shows that July, August and September are the wettest months of the year [1]. In Kouandé the mean annual precipitation is $1190 \mathrm{~mm}$ while it is $978 \mathrm{~mm}$ in Banikoara which is located a little further in the north. The annual overall mean flow at the outlet is approximately $21 \mathrm{~m}^{3} \mathrm{~s}^{-1}$ (ranging from $0 \mathrm{~m}^{3} \mathrm{~s}^{-1}$ in January to April to $250 \mathrm{~m}^{3} \mathrm{~s}^{-1}$ in September). High flows mostly occur during summer (July- August).

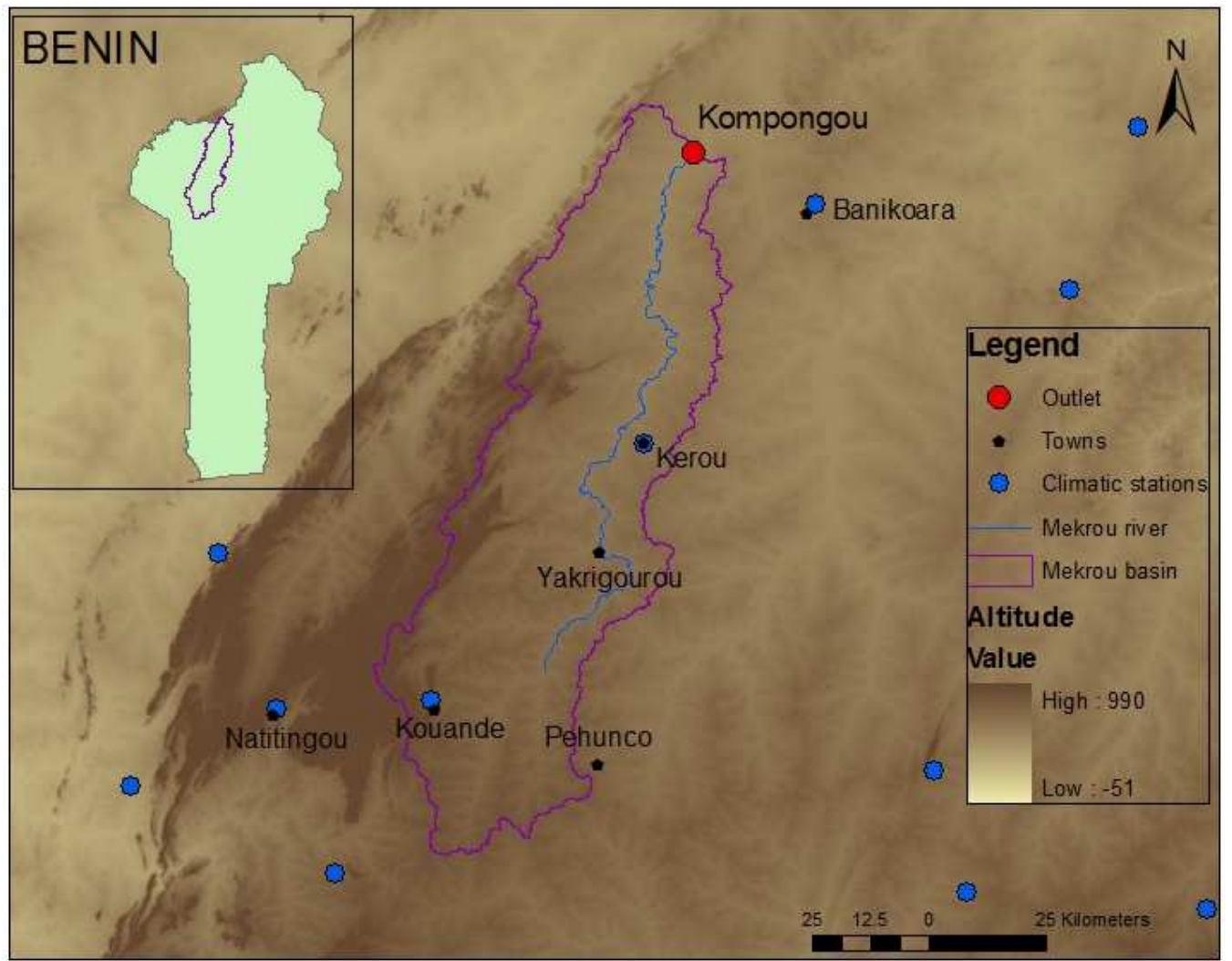

Figure 1. Location of the Mékrou catchment $\left(5708 \mathrm{~km}^{2}\right)$.

\subsection{Data}

Three types of meteorological observation datasets were used for calibration and validation of hydrological models.
First, daily precipitations were spatialised on an average basis from punctual daily precipitations measured by rainfall stations.

Second, daily discharges measurements are those of the 
outlet at Kompongou gauge. Third, daily Potential Evapotranspiration (PET) of the catchment computed by ASECNA, the national meteorological services. The Penman-Monteih formula was used for this calculation. The values computed for the synoptic station of Natitingou (see Fig.1) were the ones we used.

The precipitation data were provided by ASECNA and discharge data by DGEau, the General Water Direction of Benin.

\subsection{The Hydrological Models}

In view of these challenges and the importance of reliable data on water availability, a proper estimation of the yearly water balance requires the application of hydrological models [17]. Moreover, models are useful for researchers in order to improve the scientific knowledge of processes, for engineers for operational purposes and for decision makers for management [18]. This idea is supported by Beven (2012) who states that models of different types provide a means of quantitative extrapolation or prediction that will hopefully be helpful in decision making [19].

Three models have been chosen for our study. They are all lumped but have different structural complexity. We chose global conceptual models because their conceptual parameterization is simple and computation is efficient [20]. In addition, for regional management applications, the lumped, conceptual model has the advantage of being simpler, transparent and easier to adapt [21].

The light version of HBV model, HBV-light [22], the four-parameter model GR4J [23] and the hydrological model based on the Physics principle of Least Action MODHYPMA [24]. The two first models are conceptual, well-known and widely used. GR4J has been successfully applied on the Mékrou catchment [25]. The third model is quite new and is still under improvement. HBV has fourteen (14) parameters and works with various routines: snow, soil and routing (Fig. 2). The principle of least action belongs to the group of what we call optimisation principles. As reminded by Manton (2013), they play a fundamental role in many areas of physical science [26] leading to better numerical results.

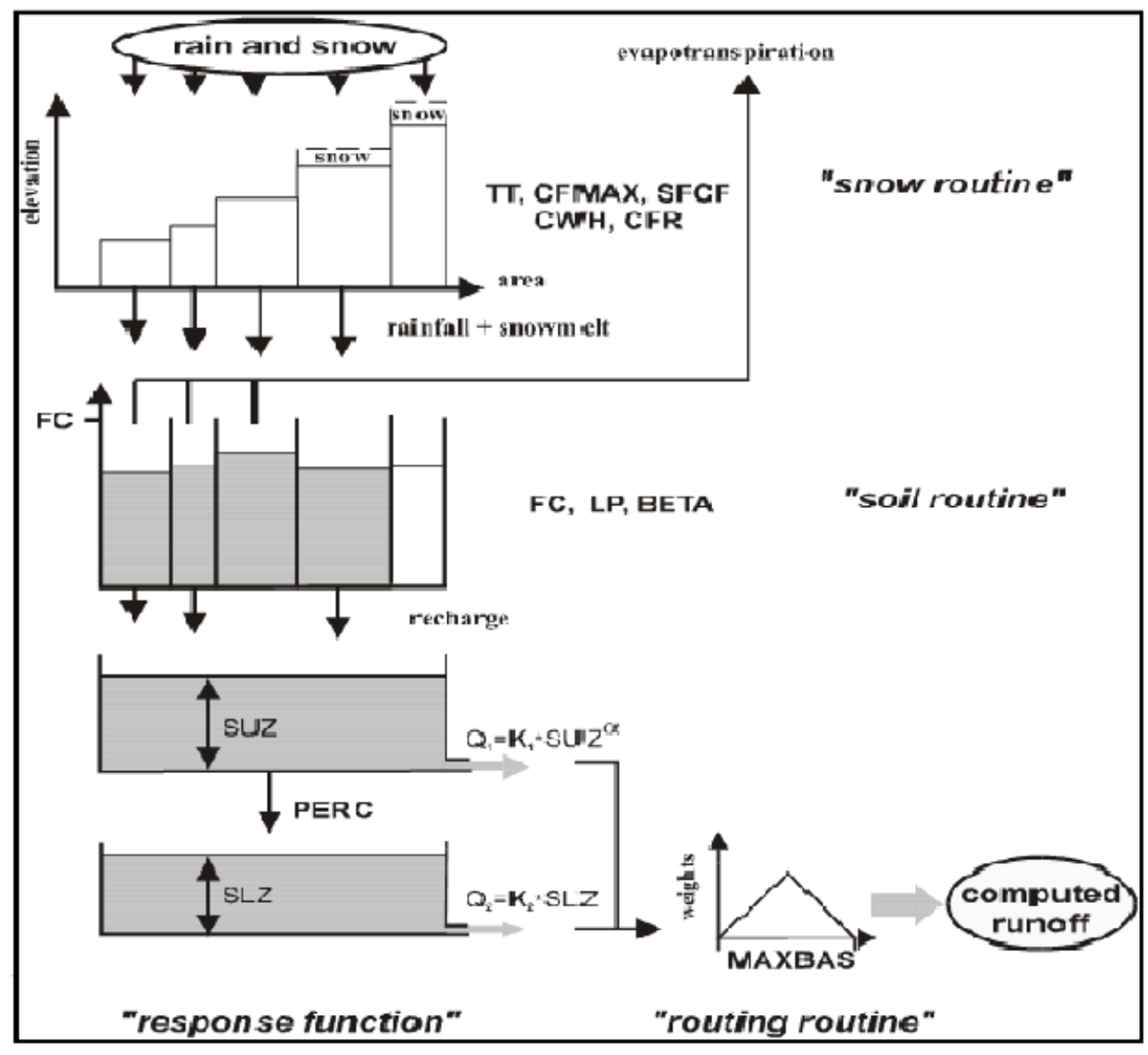

Figure 2. Schematic structure of HBV model [22].

GR4J has four (4) parameters and works with two (2) storage reservoirs (Fig. 3). 


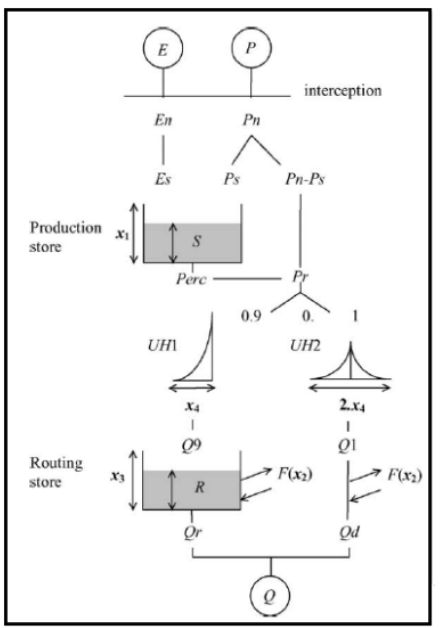

Figure 3. Schematic structure of GR4J model [23].

MODHYPMA has three parameters and is based on the Physics Principle of Least Action (Fig. 4).

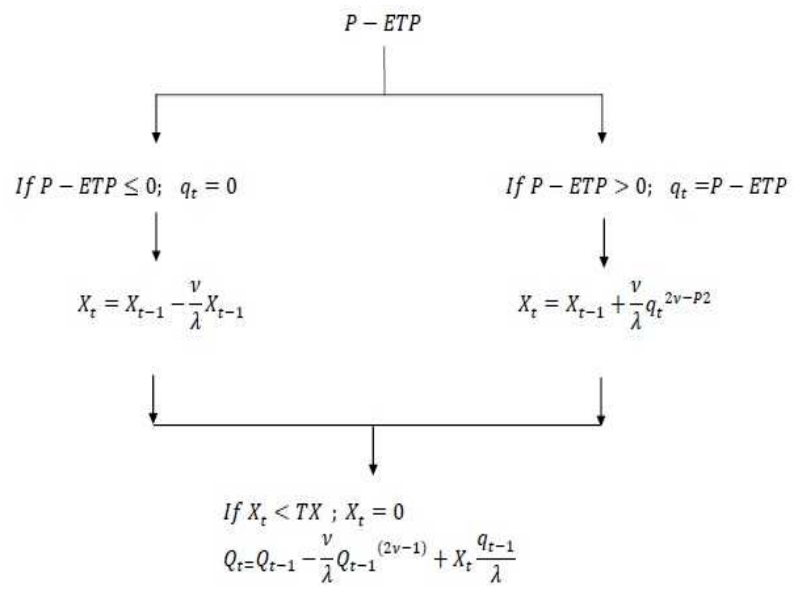

Figure 4. Schematic structure of MODHYPMA model [24].

\subsection{Calibration Scheme}

In all three hydrological models, calibration has been made in the years 2004 and 2007 while the validation has been processed on the 2010-2011 period. The very high rate of missing data along with the fact that some existing data are really questionable $[5,9]$ led us to this limited choice of data.

Automatic calibration is applied for HBV where the Nash-Sutcliffe (1970) efficiency (NSE) coefficient is used as the objective function. For the two other models, two types of calibration were applied. The very first simulations showed that the whole hydrograph is not satisfyingly simulated. Thereby, we chose to operate two types of calibrations :

- the first type is based on a good simulation of high flows which will be hereby referred to as 'Calibration H';

- the second type is based on a good simulation of low flows which will be hereby referred to as 'Calibration L';

Consequently, GR4J and MODHYPMA, for Calibration H' , have been calibrated by optimizing the Nash-Sutcliffe efficiency coefficient, which is known to well characterize high flows [27]. For Calibration L', the Logarithm transform of the Nash-Sutcliffe efficiency has been optimized. This criterion is also cited in the literature as a good estimator of low flows [28].

- In addition to these criteria, a number of others were computed:

- the NSE calculated on root squared transformed flows (NashRoot);

- the NSE calculated on log transformed flows (NashLog);

- the Kling Gupta Efficiency (KGE) [29];

- the Percent Bias (PB);

- the Absolute Percent Bias (APB);

- the weighted coefficient of determination: $\mathrm{WR}^{2}$ [30];

- the RMSE-observations standard deviation ratio (RSR) [31];

- the coefficient of determination $\left(\mathrm{R}^{2}\right)$.

The assessment of the performance was supported by visual inspection of the observed-simulated hydrographs [31].

\subsection{The Hydrological Model Ensembles}

Three ensembles were defined. The first one is the (arithmetic) mean of the simulated discharges of HBV model, GR4J model (Calibration H) and MODHYPMA (Calibration $\mathrm{H})$ on the one hand and on the second hand the (arithmetic) mean of the simulated discharges of HBV model, GR4J model (Calibration L) and MODHYPMA (Calibration L). The second ensemble is composed as the previous one of two sub-groups which are the median of the simulated discharges of HBV model, GR4J model (Calibration $\mathrm{H}$ ) and MODHYPMA (Calibration $\mathrm{H}$ ) on the one hand and on the other hand the median of the simulated discharges of HBV model, GR4J model (Calibration L) and MODHYPMA (Calibration L). The third ensemble, composed of five datasets is the median of simulated discharges and takes into account all the simulations namely HBV model, GR4J model (Calibration H) and MODHYPMA (Calibration H), GR4J model (Calibration L) and MODHYPMA (Calibration L).

Because the catchment shows an important annual cycle in the hydrological regime, we specified three distinct periods representing the beginning of the season (P1), the period of high flows (P2) and finally the recession period (P3). The periods covered by $\mathrm{P} 1, \mathrm{P} 2$ and $\mathrm{P} 3$ are detailed in Table1.

Table 1. Definition of $P 1, P 2$ and $P 3$ over the calibration and validation periods

\begin{tabular}{llll}
\hline Periods & & & \\
\hline Years & Period P1 & Period P2 & Period P3 \\
2004 & $01 / 01$ to $31 / 07$ & $01 / 08$ to $16 / 10$ & $17 / 10$ to $31 / 12$ \\
2007 & $01 / 01$ to $15 / 08$ & $16 / 08$ to $12 / 10$ & $13 / 10$ to $31 / 12$ \\
2010 & $01 / 01$ to $16 / 08$ & $17 / 08$ to $12 / 11$ & $13 / 11$ to $31 / 12$ \\
2011 & $01 / 01$ to $09 / 09$ & $10 / 09$ to $17 / 10$ & $18 / 10$ to $31 / 12$ \\
\hline
\end{tabular}

P1: Beginning of the season (rising limb)

P2:Period of high flows //// P3: Recession period

In order to compare the results of single models to those of ensembles, the criterion used was the Root Mean Squared Error (RMSE) (1). In Equation (1), $\mathrm{S}_{\mathrm{i}}$ is the simulated 
discharge for each time step, and $\mathrm{O}_{\mathrm{i}}$ is the observed value. $\mathrm{N}$ is the total number of values within the time period of analysis.

$R M S E=\sqrt{\frac{\sum_{i=1}^{N}\left(S_{i}-O_{i}\right)^{2}}{N}}$

Table 2. Daily criteria of performance for the calibration (2004 \& 2007) and validation (2010-2011) periods.

\begin{tabular}{|c|c|c|c|c|c|c|c|c|c|c|}
\hline & \multicolumn{10}{|c|}{ CRITERIA OF PERFORMANCE (CAL / VAL) } \\
\hline & & Nash & NashRoot & NashLog & KGE & $w R^{2}$ & APB & PB & RSR & $\mathrm{R}^{2}$ \\
\hline CALIBRA & $\mathrm{HBV}$ & $0.80 / 0.91$ & $0.90 / 0.95$ & $0.90 / 0.94$ & $0.73 / 0.72$ & $0.93 / 0.69$ & $0.42 / 0.29$ & $0.24 /-0.18$ & $0.44 / 0.30$ & $0.94 / 0.90$ \\
\hline \multirow[t]{2}{*}{ TION1: H } & GR4J & $0.77 / 0.86$ & $0.71 / 0.88$ & $0.38 / 0.71$ & $0.64 / 0.70$ & $0.88 / 0.66$ & $0.55 / 0.38$ & $0.35 /-0.15$ & $0.48 / 0.37$ & $0.96 / 0.93$ \\
\hline & MOD & $0.73 / 0.82$ & $0.86 / 0.83$ & $0.86 / 0.62$ & $0.58 / 0.72$ & $0.52 / 0.62$ & $0.48 / 0.45$ & $-0.22 /-0.16$ & $0.52 / 0.43$ & $0.89 / 0.86$ \\
\hline CALIBRA & GR4J & $0.72 / 0.61$ & $0.84 / 0.80$ & $0.84 / 0.90$ & $0.63 / 0.31$ & $0.56 / 0.40$ & $0.51 / 0.57$ & $-0.19 /-0.48$ & $0.53 / 0.62$ & $0.90 / 0.87$ \\
\hline TION2: L & MOD & $0.71 / 0.64$ & $0.87 / 0.83$ & $0.91 / 0.90$ & $0.57 / 0.35$ & $0.52 / 0.43$ & $0.48 / 0.53$ & $-0.22 /-0.43$ & $0.54 / 0.60$ & $0.90 / 0.90$ \\
\hline
\end{tabular}

\section{Results and Discussion}

\subsection{Simulation of Hydrological Models}

Before assessing the ensembles, each model has been evaluated separately. Table 2 summarizes the values of the criteria of performance (listed earlier) for the calibration and validation periods. Fig. 5 specifically illustrates the results of the modeling for HBV model. The three Nash criteria are greater than 0.8 ; the $\mathrm{wR}^{2}$ and $\mathrm{R}^{2}$ show particularly high values $(>0.7)$ which is very good. The APB is globally 0.4 ; this is an acceptable value. The $\mathrm{PB}$ presents also good values ranging from roughly -0.2 to 0.2 .

The visual inspection of Fig. 6 reveals that HBV model simulates more or less well the various parts of the hydrographs. This is the reason why HBV model has not been calibrated in two different modes like other models. Fig. 7 specifically illustrates the results of the modeling for GR4J model according to the various calibration modes. In 'calibration H' mode, the Nash is particularly high (around 0.8 ) unlike the NashLog which significantly lower (around 0.4). The contrary of these results is observed in the second mode.

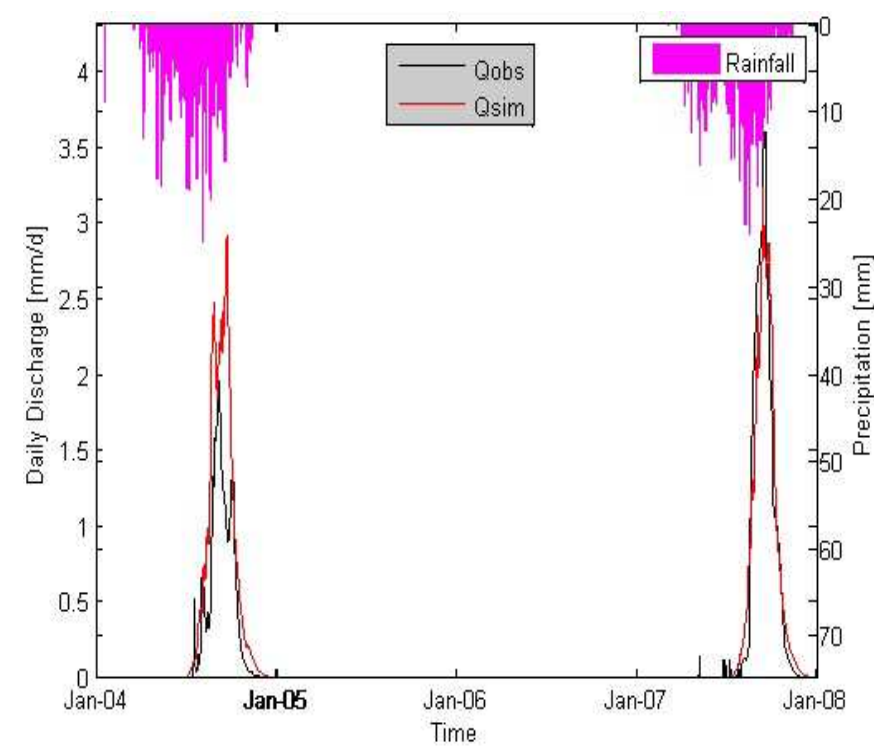

In fact, in 'calibration L' mode, the Nash is particularly low (around 0.6) while the NashLog is significantly higher (around 0.9). These results make sense when we analyze the hydrographs (Fig. 8). We can see that in mode H, high flows are better estimated than low flows especially recession flows. It is the contrary in mode L.

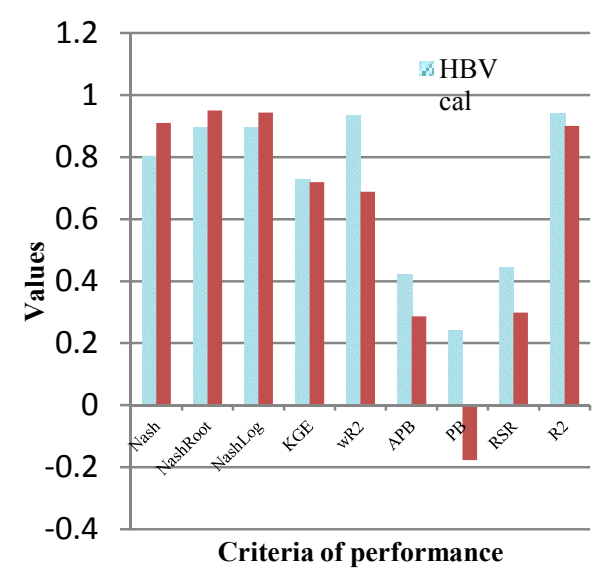

Figure 5. Criteria of performance for HBV model

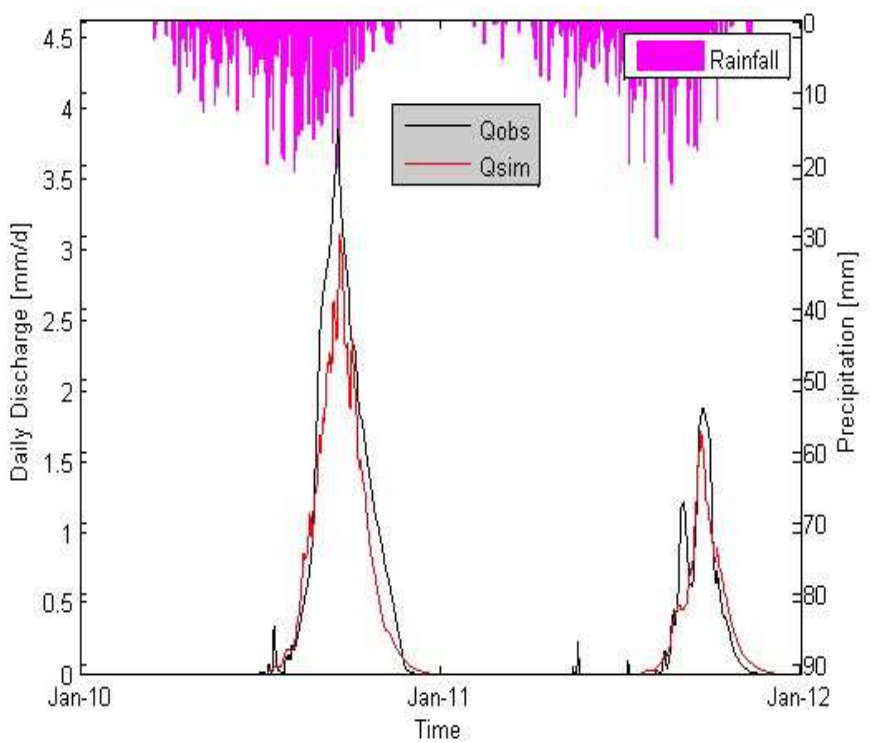

Figure 6. Observed and simulated hydrographs over the calibration (left) and validation (right) periods for HBV model 


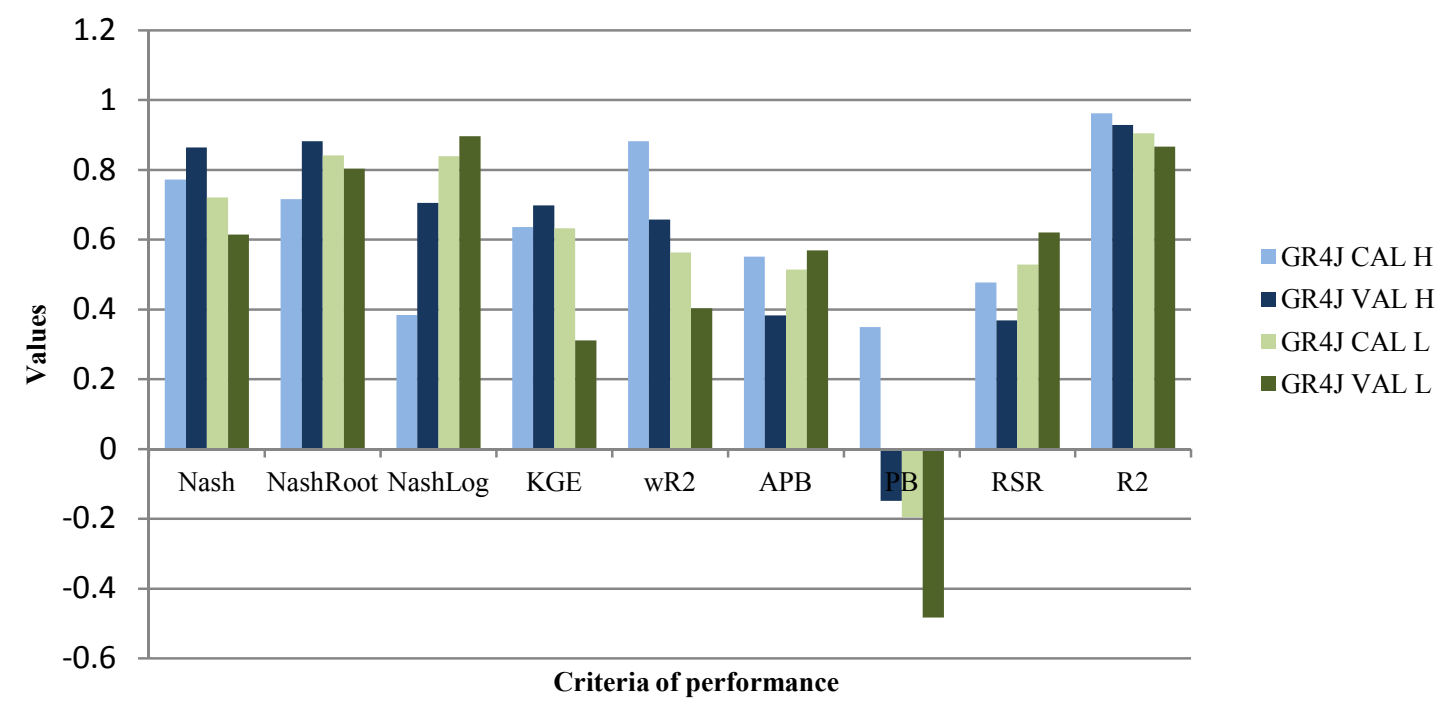

Figure 7. Criteria of performance for GR4J model according to the various calibration modes
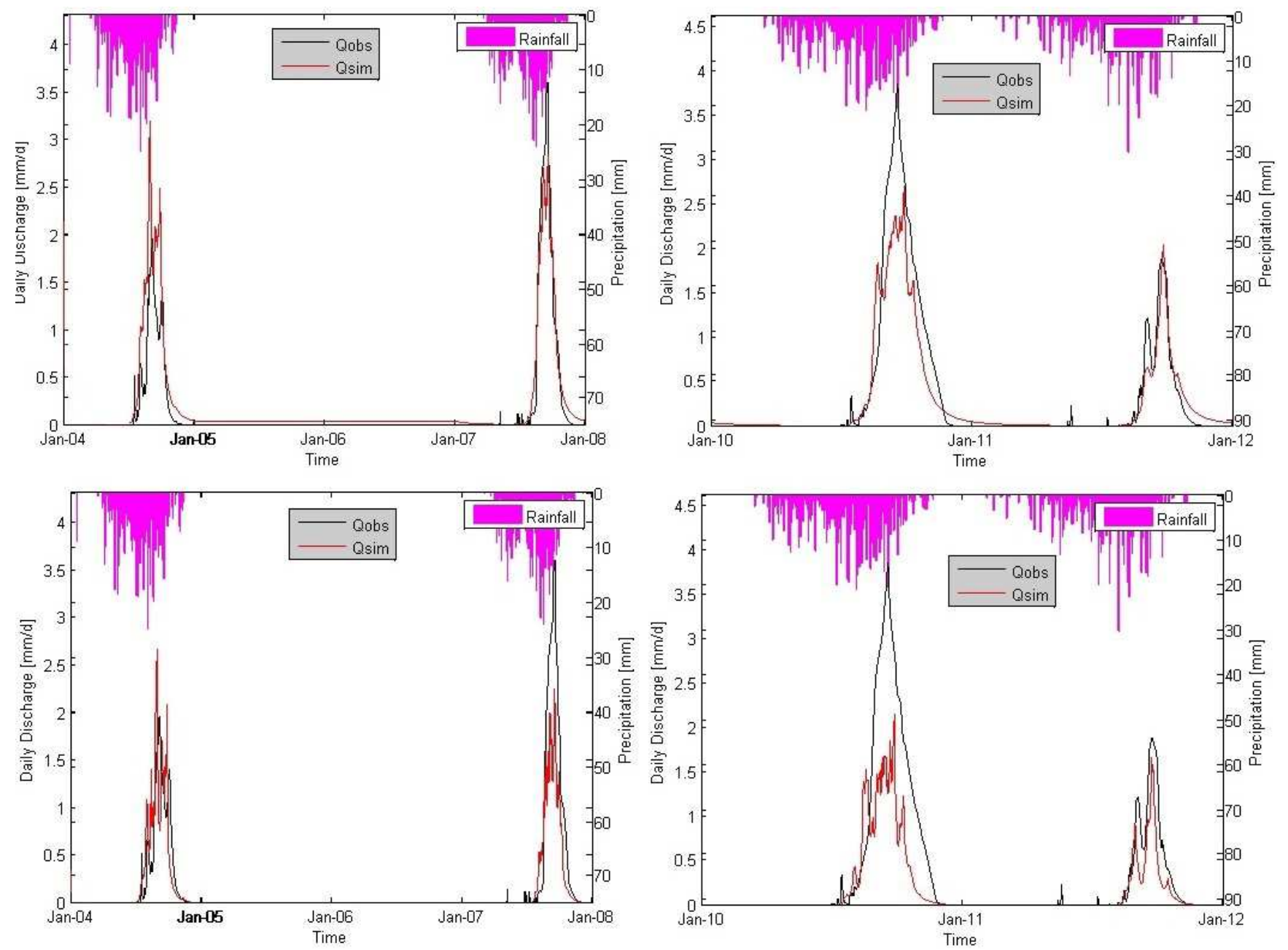

Figure 8. Observed and simulated hydrographs over the calibration (left) and validation (right) periods for GR4J model.Upper graphs are the results of Calibration $H$ and lower graphs of Calibration $L$

The values of the NashRoot are good for both modes (around 0.8 ) which is not surprising since this criterion is said to be more suitable for an all-purpose model [12]. The $\mathrm{wR}^{2}$ and $\mathrm{R}^{2}$ show particularly high values $(>0.8)$ which can be explained by the fact that simulated discharges globally follow the trend of observed ones. The APB and PB have acceptable 
values.

Fig. 9 specifically illustrates the results of the modeling for MODHYPMA model according to the various calibration modes. The analysis of Fig. 9 and the hydrographs (Fig. 10) allow us to conclude that the results of MODHYPMA are similar to those of GR4J.

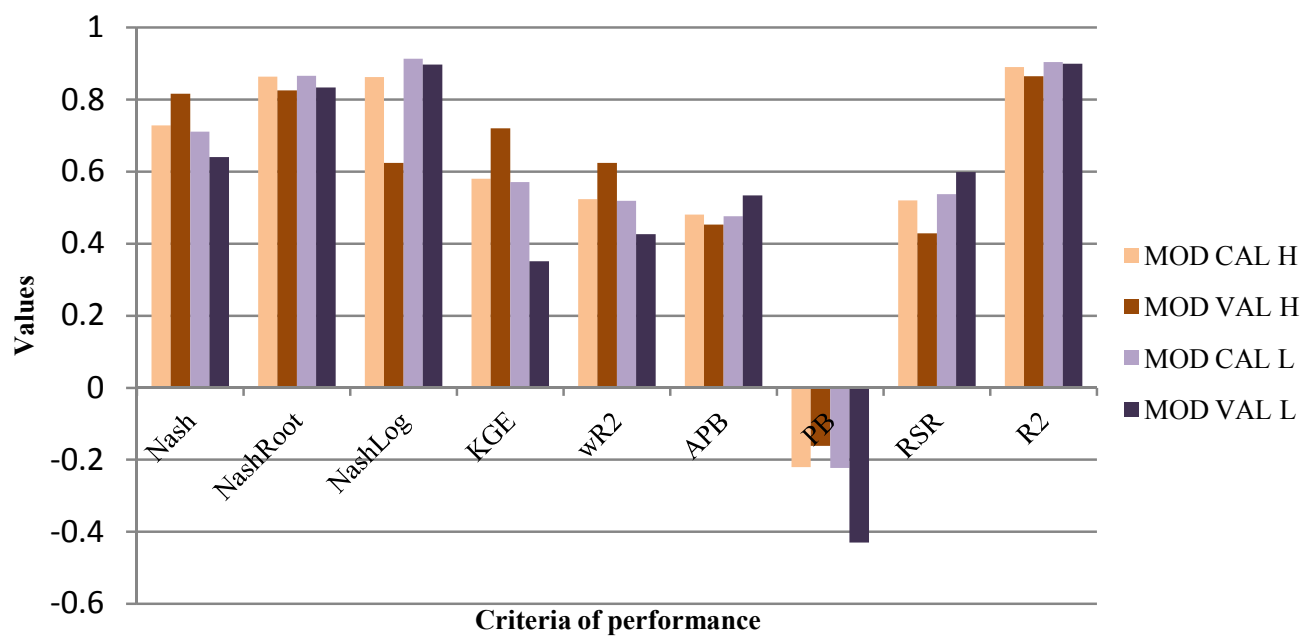

Figure 9. Criteria of performance for MODHYPMA model according to the various calibration modes
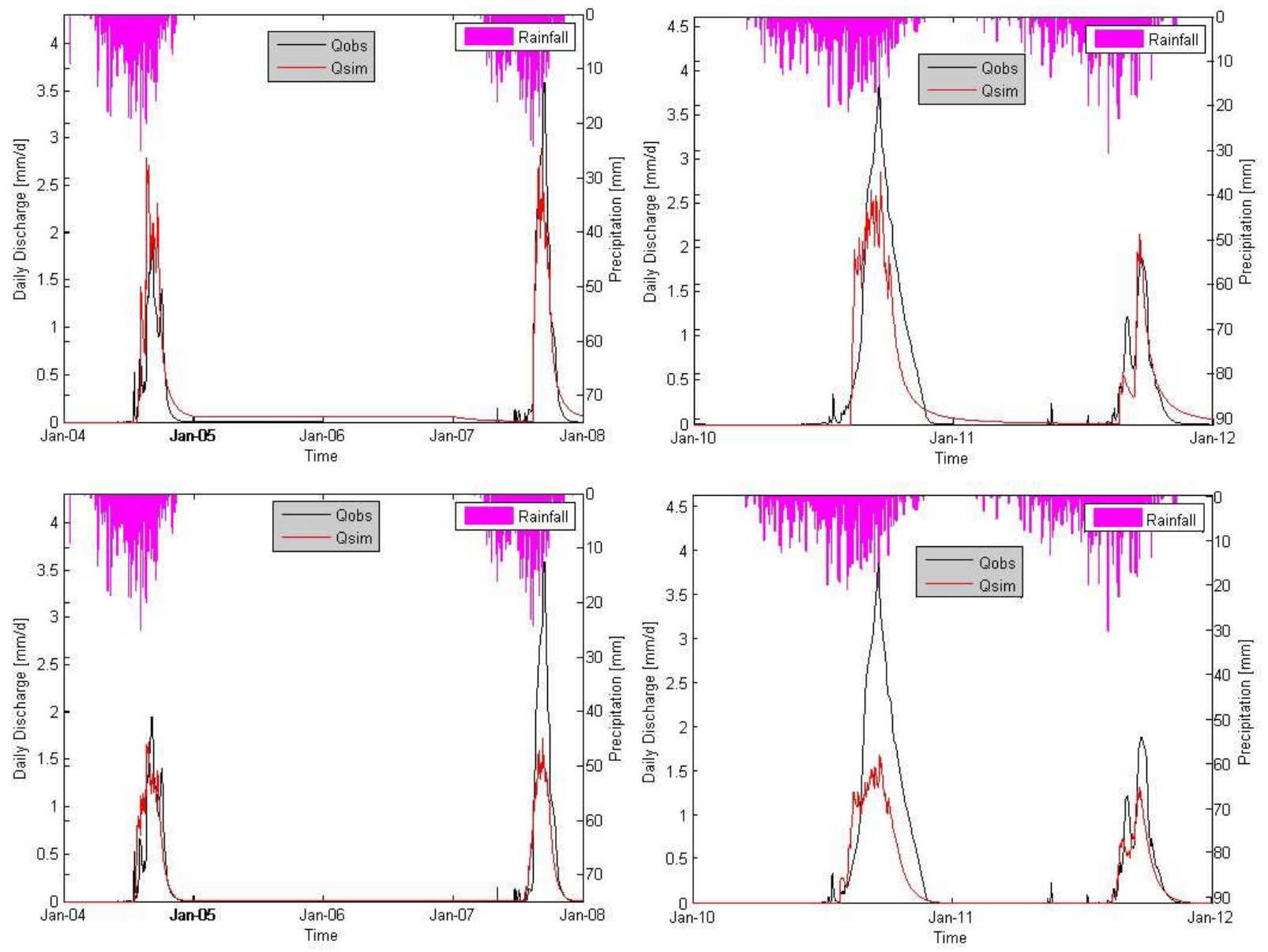

Figure 10. Observed and simulated hydrographs over the calibration (left) and validation (right) periods for MODHYPMA model .Upper graphs are the results of Calibration $H$ and lower graphs of Calibration $L$

\subsection{Simulation of Ensembles}

In this section, we examine the performance of ensembles of previously studied models. As explained before, three ensembles were defined. The ensembles give in general better RMSE values than single models. The lowest RMSE is identified for each season P1, P2 and P3. Table 3 shows that the beginning of the season (P1) is best simulated by the HBV 
model, the high flows (P2) are best simulated by the ensemble $1 \mathrm{H}$ and finally, it is the ensemble $1 \mathrm{~L}$ which best estimates the recession flows (P3). Fig. 11, 12 and 13 show the best ensembles respectively for periods $\mathrm{P} 1, \mathrm{P} 2$ and $\mathrm{P} 3$.

According to the objective of the modeling other criteria could have been chosen. Because the hydrographs were divided in three (3) parts, the RMSE appeared to be the most suitable criterion in our study. Given the fact that the values of discharge in $\mathrm{mm} / \mathrm{d}$ are quite low, a good precision was required: numbers are rounded off to four decimal places (Table 3).

The analysis of the results of simulation of the HBV model (Fig.6) shows that the beginning of season (P1) is quite well simulated.

Table 3. RMSE values calculated according to seasons $P 1, P 2$ and P3 over the calibration and validation periods

\begin{tabular}{|c|c|c|c|c|}
\hline & \multicolumn{4}{|c|}{ RMSE(mm/d) } \\
\hline \multirow{6}{*}{$\begin{array}{l}\text { CALIBRA } \\
\text { TION1 : H }\end{array}$} & & $\mathrm{P} 1$ & $\mathrm{P} 2$ & P3 \\
\hline & HBV & 0.0847 & 0.6068 & 0.0834 \\
\hline & GR4J & 0.1506 & 0.6476 & 0.1100 \\
\hline & MOD & 0.1193 & 0.6731 & 0.1214 \\
\hline & ENS $1 \mathrm{H}$ & 0.0943 & 0.5960 & 0.1014 \\
\hline & ENS $2 \mathrm{H}$ & 0.0857 & 0.5986 & 0.1090 \\
\hline \multirow{3}{*}{$\begin{array}{l}\text { CALIBRA } \\
\text { TION2: L }\end{array}$} & GR4J & 0.1093 & 0.9538 & 0.1213 \\
\hline & MOD & 0.1168 & 0.9391 & 0.0937 \\
\hline & ENS $1 \mathrm{~L}$ & 0.0979 & 0.7591 & 0.0806 \\
\hline
\end{tabular}

\begin{tabular}{lllll}
\hline \multicolumn{5}{c}{ RMSE(mm/d) } \\
\hline & ENS 2 L & 0.0966 & 0.8666 & 0.0938 \\
H \& L & ENS 3 H+L & 0.0887 & 0.6679 & 0.0843 \\
\hline
\end{tabular}

$\mathrm{P} 1$ : Beginning of the season (rising limb) ; P2:Period of high flows

P3: Recession period $/ / /$ ENS $1=$ Mean ; ENS $2=$ Median ; ENS $3=$ Median H: Calibration for High Flows /// L: Calibration for Low Flows

This result is supported by the RMSE value (0.0847) obtained for this model in Period 1. However, the RMSE value obtained for the median ensemble $2 \mathrm{H}$ is very close to this value :0.0857 vs 0.0847 (See Table 3).

Two reasons may explain why ENS $1 \mathrm{H}$ gave the best RMSE value $(0.5960)$ for the high flows period (P2). First, the high flows are better simulated by the models in calibration $\mathrm{H}$. Second, the years 2004 and 2011 are drier so the models have overestimated them (especially year 2004) in contrary to years 2007 and 2010 that were a little underestimated. With this configuration, we can expect the mean ensemble to be closer to the observations than the median ensemble.

The recession period (P3) is better simulated by the models in calibration L. Yet, there is a slight underestimation of these flows by GR4J calibration L and MODHYPMA calibration L and a slight overestimation by HBV.

Longer datasets may be useful in order to confirm those results.

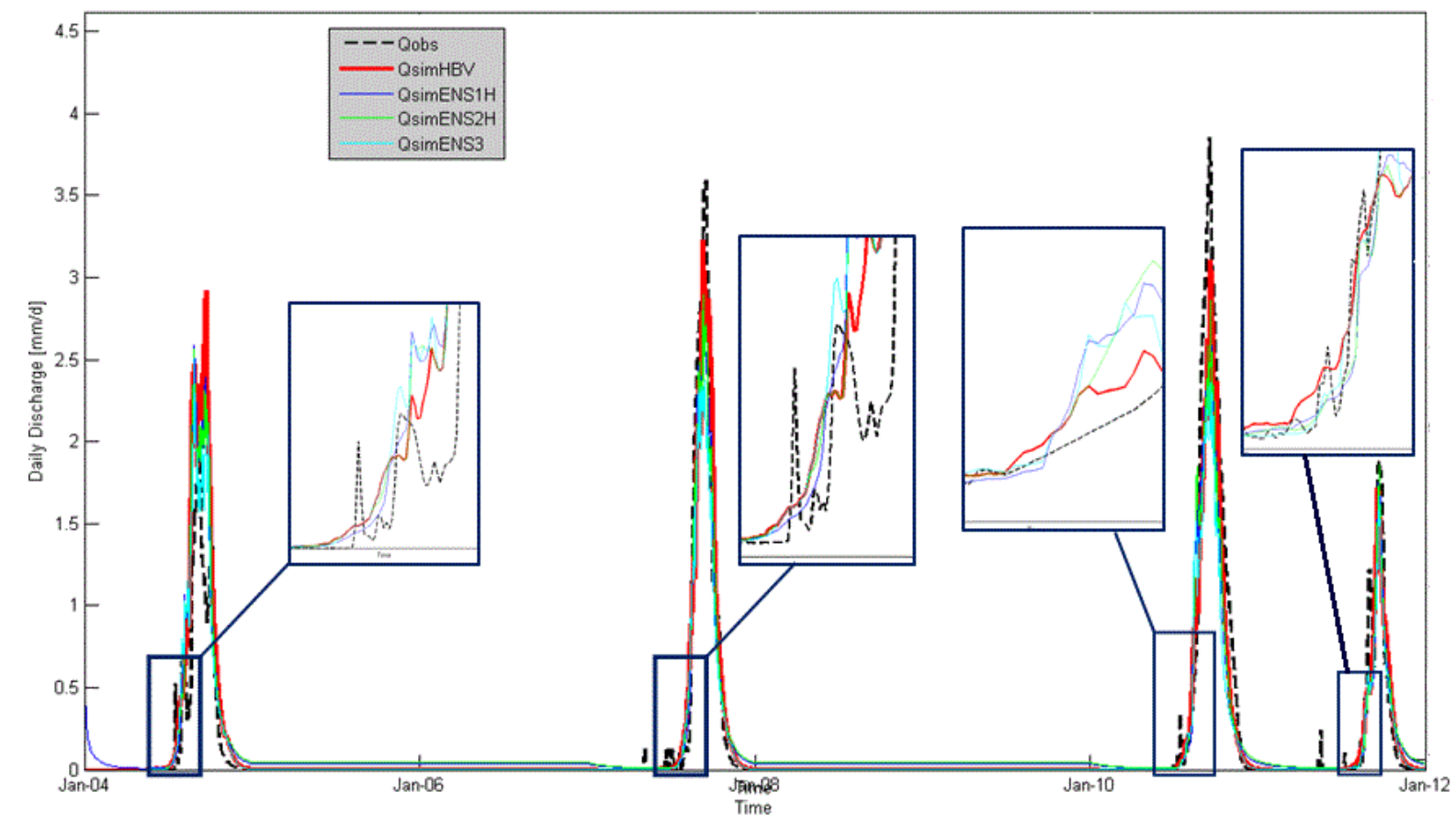

Figure 11. Best ensemble simulation for Period 1 : HBV(hydrographs in red colour). Observations are in dash and black colour 


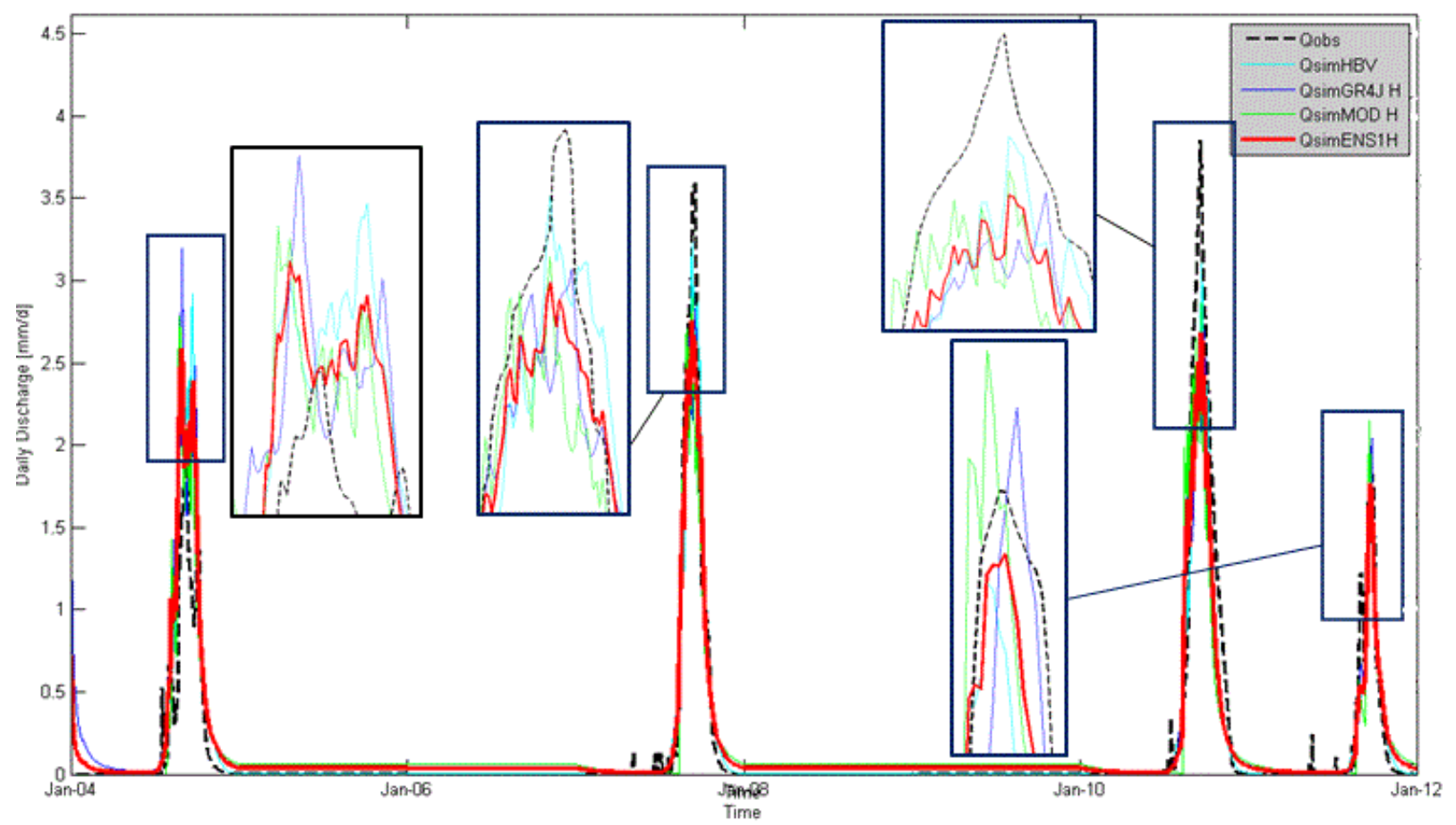

Figure 12. Best ensemble simulation for Period 2 : ENSEMBLE 1H(hydrographs in red colour). Observations are in dash and black colour

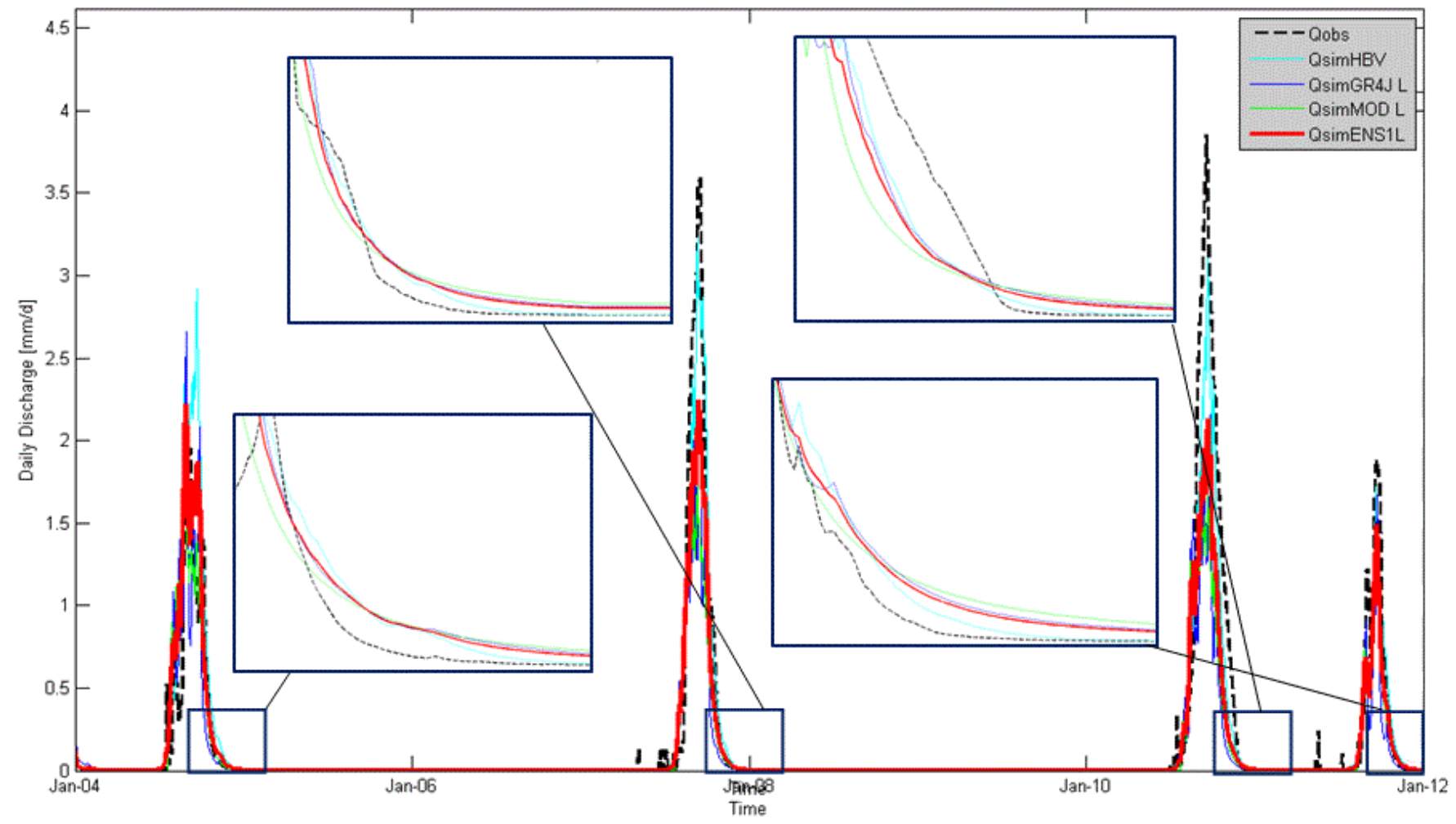

Figure 13. Best ensemble simulation for Period 3 : ENSEMBLE $1 L$ (hydrographs in red colour). Observations are in dash and black colour

\section{Conclusion}

The use of ensemble models is becoming more and more frequent in the analysis of the hydrological dynamics of a catchment. This approach is especially relevant as one single model can hardly describe the complexity of this natural system. One example has been applied in this paper for the case of Mékrou catchment in Niger basin. A double calibration appeared to be indicated in order to better simulate the observed flows. The ensemble-mean showed best values of RMSE. These results suggest that an ensemble could be considered required to fully estimate the various parts of the 
hydrographs. In this study, we used a limited number of elements in the various ensembles; we also tested only mean and median ensembles; further studies could develop more elaborated ensembles. The implementation and testing of other ensembles may be of great interest. Moreover, in this study only simple models were used, this work can be extended to more complex models like distributed models. These results are dependant on the data, there is a need to validate the results on longer datasets. An uncertainty analysis that would account for both data and models uncertainties would also bring more robustness.

\section{Acknowledgments}

The hydro-climatic data has been processed and supplied by ASECNA and DG-Eau. Financial support for the undertaking of this work has been granted by the West African Science Service Center on Climate Change and Adapted Land Use (WASCAL).

\section{References}

[1] GLEauBe. Etude portant état des lieux et gestion de l'information sur les ressources en eau dans le basin de la Mékrou. Cotonou, Benin; 2012.

[2] Kerres M. Adaptation to Climate Change in the Upper and Middle Niger River Basin.; 2010.

[3] Diekkrueger B, Busche H, Klose A, Klose S, Rademache C, Schulz O. The global dimensions of change in River Basins. Threats,Linkages And Adaptation. In: Impact of Global Change on hydrology and soil degradation - Scenario analysis for the semi-arid Drâa catchment (South Morocco). Bonn, Germany; 2010:13.

[4] Lawin AE, Afouda A. Analyse de la Variabilité du Régime Pluviométrique dans la Région Agricole d ' Ina au Bénin. Eur J Sci Res. 2011;50(3):425-439. Available at: http://www.eurojournals.com/ejsr.htm.

[5] Amogu O, Descroix L, Yéro KS, et al. Increasing River Flows in the Sahel? Water. 2010;2(2):170-199. doi:10.3390/w2020170.

[6] Aggarwal PK, Singh AK. Implications of Global Climatic Change on Water and Food Security. In: Ringler C, Biswas AK, Cline S, eds. Global Change: Impacts on Water and food Security. Water Resources Development and Management. Berlin, Heidelberg: Springer Berlin Heidelberg; 2010:49-63. doi:10.1007/978-3-642-04615-5.

[7] Brookes JD, Ainger CM, Howe C, Norton JW, Schladow G. Water and climate change: challenges for the 21 st century. J Water Clim Chang. 2010;01(1):1. doi:10.2166/wcc.2010.100.

[8] Huntington TG. Evidence for intensification of the global water cycle: Review and synthesis. J Hydrol. 2006;319(1-4):83-95. doi:10.1016/j.jhydrol.2005.07.003.

[9] Global Water Partnership West Africa. Running Water:The Mékrou Project. GWP West Africa. 2014;(19):18. Available at: www.gwpao.org.
[10] Global Water Partnership. The Project on the Mekrou River launched. Glob Water Partnersh. 2014. Available at: http://www.gwp.org/GWP-Afrique-Ouest/GWP-in-Action/PR OJET-MEKROU/Activites--Actualites/Lancement-du-ProjerMekrou/.

[11] Velázquez J a., Schmid J, Ricard S, et al. An ensemble approach to assess hydrological models' contribution to uncertainties in the analysis of climate change impact on water resources. Hydrol Earth Syst Sci. 2013;17(2):565-578. doi:10.5194/hess-17-565-2013.

[12] WMO. Hydrological forecasting.; 2004.

[13] Carpenter TM, Georgakakos KP. Impacts of parametric and radar rainfall uncertainty on the ensemble streamflow simulations of a distributed hydrologic model. J Hydrol. 2004;298(1-4):202-221. doi:10.1016/j.hydrol.2004.03.036.

[14] Todini E. Hydrological catchment modelling: past, present and future. Hydrol Earth Syst Sci. 2007;11(1):468-482. doi:10.5194/hess-11-468-2007.

[15] Beven K. Towards integrated environmental models of everywhere: uncertainty, data and modelling as a learning process. Hydrol Earth Syst Sci. 2007;11(1):460-467. doi:10.5194/hess-11-460-2007.

[16] Benoit M. Statut et usages du sol en peripherie du parc national $\mathrm{du}$ «W» du Niger. Tome 1 Contribution à l'étude du milieu naturel et des ressources végétales du canton de Tamou et du Parc du «W ». Paris, France et Niamey, Niger; 1998.

[17] Cornelissen T, Diekkrüger B, Giertz S. A comparison of hydrological models for assessing the impact of land use and climate change on discharge in a tropical catchment. J Hydrol. 2013;498:221-236. doi:10.1016/j.jhydrol.2013.06.016.

[18] Alamou E. Application du Principe de Moindre Action à la Modélisation Pluie-débit. 2011.

[19] Beven K. Rainfall-Runoff Modelling. 2nd ed. Chichester, UK: John Wiley \& Sons, Ltd; 2012. doi:10.1002/9781119951001.

[20] Yu Z. Hydrology. Modeling and Prediction. Las Vegas; 2002. doi:10.1006/rwas.2002.0172.

[21] Bormann H, Giertz S, Diekkrüger B. Hydrological catchment models: process representation, data availability and applicability for water management - case study for Benin. In: Regional Hydrological Impacts of Climatic Change-Impact Assessment and Decision Making. Foz do Iguaçu, Brazil: IASH Publications; 2005:86-93.

[22] Seibert J. HBV light. Version 2. User' s Manual. Stockholm; 2005.

[23] Perrin C, Michel C, Andréassian V. Improvement of a parsimonious model for streamflow simulation. J Hydrol. 2003;279:275-289. doi:10.1016/S0022-1694(03)00225-7.

[24] Afouda A, Alamou E. Modèle hydrologique basé sur le Principe de Moindre Action (MODHYPMA). Ann des Sci Agron du Bénin. 2010;13(1):23-45.

[25] Vissin E. Impact de la variabilité climatique et de la dynamique des états de surface sur les écoulements du bassin béninois du fleuve Niger. 2007.

[26] Manton NS. The Principle of Least Action in Dynamics. Cambridge,UK; 2013. 
[27] Legates DR, McCabe Jr. GJ. Evaluating the use of "goodness-of-fit" measures in hydrologic and hydroclimatic model validation. Water Resour Res. 1999;35(1):233-241.

[28] Pushpalatha R, Perrin C, Moine N Le, Andréassian V. A review of efficiency criteria suitable for evaluating low-flow simulations. J Hydrol. 2012;420-421:171-182. doi:10.1016/j.jhydrol.2011.11.055.

[29] Gupta H V., Kling H, Yilmaz KK, Martinez GF. Decomposition of the mean squared error and NSE performance criteria: Implications for improving hydrological modelling. J Hydrol. 2009;377(1-2):80-91. doi:10.1016/j.jhydrol.2009.08.003.
[30] Krause P, Boyle D, Bäse F. Comparison of different efficiency criteria for hydrological model assessment. Adv Geosci. 2005;(5):89-97. Available at: http://www.adv-geosci.net/5/89/2005/adgeo-5-89-2005.html. Accessed June 24, 2014.

[31] Moriasi DN, Arnold JG, Liew MW Van, Bingner RL, Harmel $\mathrm{RD}$, Veith TL. Model evaluation guidelines for systematic quantification of accuracy in watershed simulations. Am Soc Agric Biol Eng. 2007;50(3):885-900. 